\title{
Risk factors of isoniazid mono-resistance among pulmonary tuberculosis patients at Central Chest Institute of Thailand
}

\author{
Phenlak Kaewthong1, \\ Pramote Tragulpiankit ${ }^{*}$, \\ Chareon Chuchottaworn ${ }^{2}$, \\ Sukanya Wattanapokayakit ${ }^{3}$, \\ Suppanut Prakongsup ${ }^{3}$, \\ Nuanjun Wichukchinda ${ }^{3}$, \\ Surakameth Mahasirimongkol ${ }^{3}$ \\ ${ }^{1}$ Faculty of Pharmacy, Department of \\ Pharmacy, Mahidol University, Bangkok, \\ Thailand \\ ${ }^{2}$ Central Chest Institute of Thailand, \\ Nonthaburi, Thailand \\ ${ }^{3}$ Department of Medical Sciences, \\ Ministry of Public Health, Nonthaburi, \\ Thailand
}

*Corresponding author: Pramote Tragulpiankit pramote.tra@mahidol.ac.th

\section{KEYWORDS:}

Isoniazid mono-resistance; Risk factors; Thai pulmonary tuberculosis patients; Rapid acetylator; $N$-acetyltrasferase 2 (NAT2)

https://www.pharmacy.mahidol.ac.th/journal/ (c) Faculty of Pharmacy, Mahidol University (Thailand) 2020

\begin{abstract}
Risk factors of isoniazid mono-resistance were reported by $\mathrm{N}$-acetyltransferase 2 (NAT2) gene and some clinical factors in the literature. This study aimed to determine the risk factors of isoniazid mono-resistance among Thai pulmonary tuberculosis patients. The case-control study was conducted from $18^{\text {th }}$ September 2017 to $20^{\text {th }}$ February 2018. Demographic data were collected from medical record review and interview. NAT2 genotypes were collected from saliva samples collection and determined by multiplex polymerase chain reaction and gel electropherosis. Risk factors were conducted by multivariate logistic regression analysis and strength of association was reported as odd ratio with $95 \%$ confident interval. Total 167 participants comprised of 50 isoniazid mono-resistant and 117 drug-susceptible tuberculosis patients. NAT2*4/*6A was the most common genotype in both $12(24.0 \%)$ cases and $38(32.5 \%)$ controls, respectively, and there was not significantly different among genotypes between two groups ( $p$-value $=0.352$ ). Moreover, rapid acetylator was not significantly associated with isoniazid mono-resistance compared with slow acetylator (OR 1.169; 95\% CI $0.435-3.140, p$-value $=0.389)$. Adults who were less than 50 years old were more likely to develop isoniazid mono-resistance (adjusted OR 2.281; 95\%CI 1.101-4.728, $p$-value $=0.027$ ) than elderlys who were older than 50 years old. In contrast, ever-drinkers were less likely to develop isoniazid mono-resistance (adjusted OR 0.417; $95 \% \mathrm{CI} 0.207-0.842, p$-value $=0.015$ ). In conclusion, the young adults and never-drinkers are risk factors of isoniazid monoresistance in these Thai pulmonary tuberculosis patients. Moreover, a further study is needed to clarify the role of NAT2 on isoniazid mono-resistance in Thais.
\end{abstract}

\section{INTRODUCTION}

Recently, tuberculosis (TB) has become the first leading cause of death from infectious diseases since 2016. Thailand is one of top 20 countries with a high burden of TB. Moreover, the situation of drug-resistant tuberculosis (DR-TB), especially isoniazid mono-resistance, has been widely increased in many regions of Thailand. According to the trends from four national antiTB drugs resistance surveillances in Thailand, the percentage of the resistance among new patients increased from 5.30 - 6.54\%; likewise, the percentage of the resistance among previously treated patients definitely increased from $4.10-9.69 \%$ during 1997 and 
2013. Moreover, patients with isoniazid monoresistance are more likely to have poor treatment outcomes, comprising treatment failure, default, relapse, and death ${ }^{1}$.

Pharmacogenetics is a key area for global modern medical treatment for the last decades because pharmacogenetics provide healthcare providers with the predictive capability of the individual response to drugs based on genetic inheritance of patients. At present, poor treatment outcomes of several diseases and adverse effects from several drugs, for example carbamazepine, allopurinol, clopidogrel, and abacavir, have been significantly improved with pharmacogenomic information ${ }^{2}$. Similarly, the efficacy of TB treatment and adverse drug reactions (ADRs) from anti-TB drugs are also related to pharmacogenomic information, but with less certainty compared to other recommendation in the Clinical Pharmacogenetics Implementation Consortium (CPIC).

Isoniazid (INH) is one of the most important oral anti-TB drugs among first-line anti-TB drugs (FLDS), and it is mainly metabolized by two key enzymes from liver and intestine, i. e. arylamine $N$-acetyltransferase 2 (NAT2) enzyme and microsomal cytochrome P450 2E1 (CYP2E1). NAT2 enzyme is encoded by the NAT2 gene which is located on chromosome 8p22 and has a 970 bp coding exon. To our knowledge, polymorphisms of NAT2 gene, which varied among each population with different ethnicities, are attributed to various single nucleotide polymorphisms (SNPs), and it also impacts on the capability of NAT2 enzyme in term of acetylation ${ }^{3}$. Theoretically, NAT2*4 is called wild-type allele which is absent of SNPs, and it is classified into fast allele whereas some fast alleles with the presence of SNPs, i.e. NAT2 $* 11 A, N A T 2 * 12 A, N A T 2 * 13 A$ are classified into variant alleles. On the other hand, other alleles with the presence of SNPs, i.e. NAT2 *5B, NAT2 $* 6 A, N A T 2 * 7 B$ are slow alleles. As a consequence, acetylator phenotypes were classified into three phenotypes, i. e. rapid acetylator, intermediate acetylator, and slow acetylator phenotypes, depending on their genotypes ${ }^{4}$. Interestingly, polymorphisms of NAT2 gene vary noticeably among each population with different ethnicity or different origin. Based on the previous studies, NAT2 $* 5$ was common among Arabs, Americans, Indians, Caucasians, and Black South Africans, followed by NAT2 $* 6^{5-7}$. On the other hand, NAT2 * 4 was the most frequent allele among Asians, including Chinese, Japanese, Indonesian, and Thai population, followed by NAT2 * $6^{8-10}$.
Moreover, the difference of acetylator phenotypes in individual patient influenced the rate of INH elimination; for examples, the plasma half-life of patients with slow acetylator was 2. 00-4. $50 \mathrm{hr}$ whereas the plasma half-life of patients with rapid acetylator was $0.75-1.80 \mathrm{hr}$. In Thailand, Wattanapokayakit $S$, et al revealed that $71.1 \%$ Thais with anti-TB drug-induced liver injury (AT-DILI) had slow acetylator phenotypes whereas a majority of Thais who tolerate anti-TB drugs had intermediate acetylator phenotype; moreover, patients with slow acetylator were at high risk to develop AT-DILI (OR 8.80; 95\% CI 4.01-19.31, $p$-value $\left.=1.53 \times 10^{-8}\right)^{11}$. However, there was no association reported between isoniazid mono-resistance and NAT2 acetylator status.

From the literature review, 14 factors from 13 studies were considered as important risk factors of isoniazid mono-resistance among TB patients due to the fact that $p$-value of each risk factor was lower than 0.05 . These risk factors consisted of 1) male ( $p$-value $=0.036), 2)$ some ethnicities: Asians, Pacific Islanders, Black Caribians ( $p$-value $<0.001$ ), 3 ) some occupations: employees, unemployed persons, drug dealers, and sex workers $(p$-value $<0.001), 4)$ living in prison $(p$-value $<0.001), 5)$ smoking $(p$-value $=$ $0.021), 6)$ illicit drug use $(p$-value $=0.001), 7)$ TB contact $(p$-value $=0.011), 8)$ previously treated patients $(p$-value $=0.038), 9)$ history of TB infection ( $p$-value < 0.050$), 10)$ chronic obstructive pulmonary disease $(\mathrm{COPD})(p$-value $=0.042), 11)$ Diabetes Mellitus $(\mathrm{DM})(p$-value $=0.012), 12)$ HIV seropositive ( $p$-value $<0.050), 13$ ) cavities in lungs ( $p$-value $=0.019)$ and 14) homelessness $(p \text {-value }=0.033)^{12-24}$. In Thailand, Traisathit $\mathrm{P}$, et al revealed that relapsed patients were significantly associated with isoniazid monoresistance (OR 5. 5; 95\% CI 2. 30-13. 00); nevertheless, other previous studies associated with risk factors of isoniazid mono-resistance among Thais were rarely reported in Thailand ${ }^{25}$. As a result, the present study performed to identify characteristics of the NAT2 genotypes and other clinical risk factors of isoniazid monoresistance.

\section{MATERIALS AND METHODS}

\subsection{Study design}

This study was a case-control study, conducted at the TB clinic, Central Chest Institute of Thailand, Nonthaburi from $18^{\text {th }}$ September 
2017 to $20^{\text {th }}$ February 2018, comparing the difference between isoniazid mono-resistant group (cases) and drug-susceptible tuberculosis (DS-TB) group (controls). The registry books of TB clinic were routinely performed to monitor TB patients. Eligible participants were recruited by these inclusion criteria as follows 1) Thai males and females were at least 18 years old, 2) they were diagnosed with pulmonary tuberculosis, 3) they had the results of sputum culture isolated of Mycobacterial tuberculosis (M. Tuberculosis), the results of chest radiographic finding, and the results of drug susceptibility testing (DST) documented in medical records. In contrast, the exclusion criteria were as follows 1) patients were diagnosed with extrapulmonary tuberculosis, 2) patients had any history of non-compliance during treatment, and 3) they denied to participate in this study.

\subsection{Sample size}

The sample size calculation of this study was calculated based on a case to control of 1:2. It was assumed that type 1 error $(\alpha)$ was 0.05 (confident level of $95 \%$ ) and type $2(\beta)$ error was 0.20 (power of $80 \%$ ). Due to the fact that the association between NAT2 rapid acetylator status and isoniazid mono-resistance has not been studied among Thai population, the information used for sample size calculation was obtained from the study of Wattanapokayakit S, et al ${ }^{11}$. In Thailand, the proportion of isoniazid monoresistant patients with rapid acetylator status was 0.20 whereas the proportion of non-isoniazid mono-resistant patients with rapid acetylator status was 0.05 . It was assumed that the expected odds ratio between isoniazid mono-resistant patients with rapid acetylator status and nonisoniazid mono-resistant patients with rapid acetylator status was four. Therefore, the sample size was 141; however, the sample size was increased by $20 \%$ of the sample size to prevent data loss because of incomplete data or withdrawal of some participants from the study. Therefore, the number of participants in this study was recruited by 177 participants (59 cases and 118 controls).

\subsection{Ethical approval}

The protocol of this study was conducted under the approval of Faculty of Dentistry / Faculty of Pharmacy Mahidol University
Institutional Review Board (MU-DT/ PY-IRB 2017/ 031. 1605) and the approval of Ethics Committee of Central Chest Institute of Thailand (COA.No.039/2560).

\subsection{Data collection}

General characteristics and sociodemographic data were collected by face to face interview. For alcohol consumption assessment, a chart of Thai drinking survey guide ${ }^{26}$, which consisted of the pictures of beverages and volume of containers (mL), was demonstrated to participants. Then, each participant was asked about the type of beverages, the volume of containers, and the frequency of alcohol consumption in which he/ she drank in the past. Next, the researcher was able to calculate the intensity of alcohol (g), total annual consumption (g), and average daily consumption (g). Moreover, clinical characteristics were collected by medical record review. After data collection had been completed, saliva sample ( $2 \mathrm{~mL}$ each) was collected from each participant into SalivaGene $^{\circledR}$ Collection Module II (Stratec ${ }^{\circledR}$, Germany) and stored in $8^{\circ} \mathrm{C}$ refrigerator until further processing.

\subsection{NAT2 genotyping}

All procedures of NAT2 genotyping were conducted at the Department of Medical Sciences. Genomic DNA mini kits for tissue (the Geneaid, Taiwan) were used and applied to extract genomic DNA from each saliva sample. Next, NanoDrop 2000C spectrophotometer (Thermo Fisher Scientific, USA) was used to assess the purity of DNA solution by calculating the ratio of absorbance at 260-280 nm before multiplex polymerase chain reaction (PCR). This procedure was performed to amplify the coding region of NAT2 on BIO-RAD T100 Thermo cycler (BIO-RAD, USA); each reaction mixture contained $1 \mu \mathrm{L}$ genomic DNA, $5 \mu \mathrm{L}$ KAPA2G fast multiplex (2X) (KAPABIOSYSTEM, US), 2 $\mu \mathrm{L}$ nuclease-free water, and primer. PCR conditions were as follows initial denaturation at $95^{\circ} \mathrm{C}$ for $5 \mathrm{~min}$, followed by 31 cycles of denaturation at $95^{\circ} \mathrm{C}$ for $20 \mathrm{~s}$, annealing at $64.5^{\circ} \mathrm{C}$ for $30 \mathrm{~s}$, and extension at $72^{\circ} \mathrm{C}$ for $30 \mathrm{~s}$. These cycling reactions were followed by a final extension at $72^{\circ} \mathrm{C}$ for $3 \mathrm{~min}$. After the procedure of multiplex PCR had been finished, each DNA solution was prepared and added into agarose gel $(2 \% \mathrm{w} / \mathrm{v})$ for gel electrophoresis. Then, each 


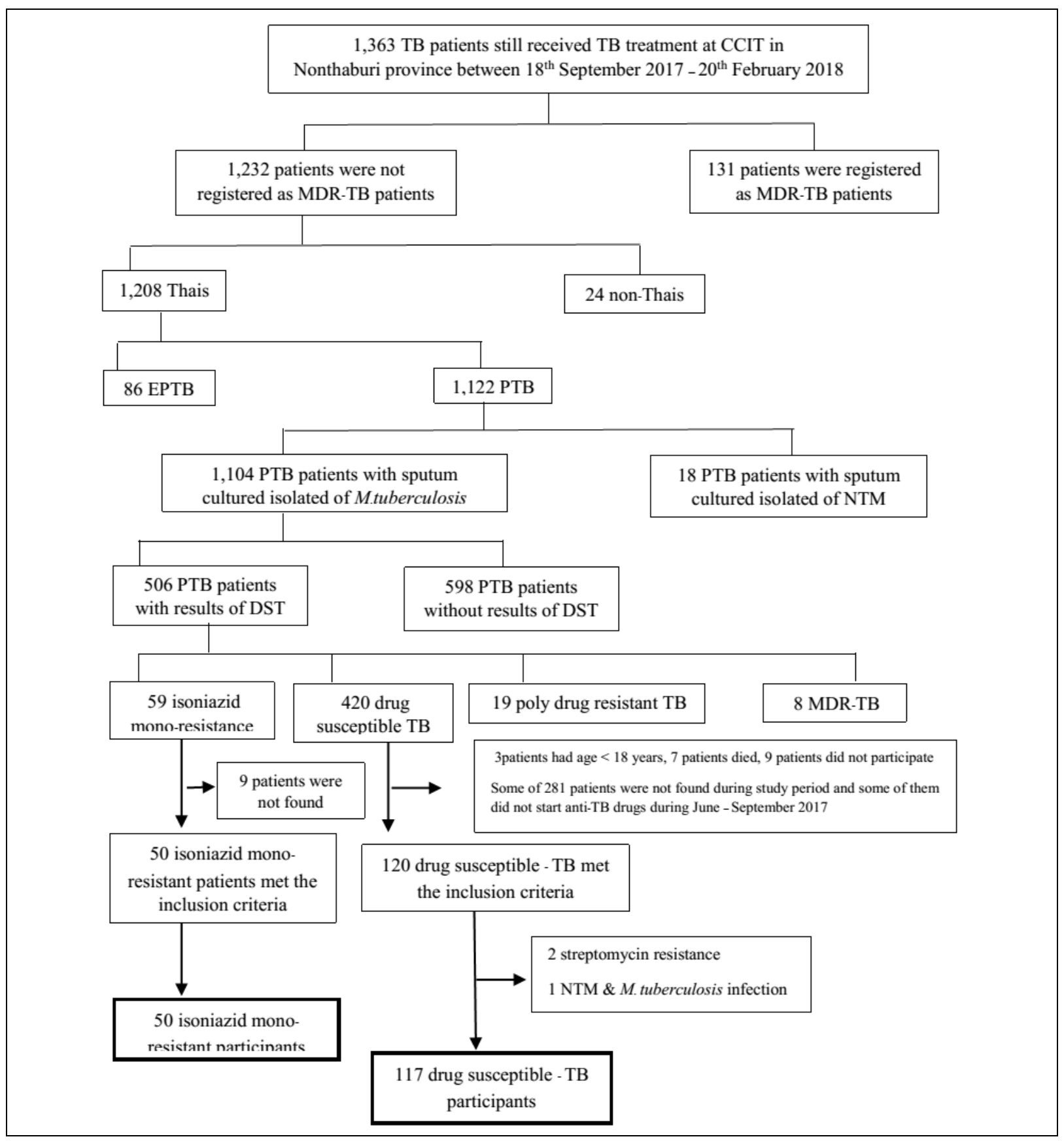

Figure 1. Flow diagram of participant recruitment; CCIT= Central Chest Institute of Thailand; $\mathrm{TB}=$ Tuberculosis; MDR-TB $=$ Multidrug-resistant tuberculosis; EPTB $=$ Extrapulmonary tuberculosis; PTB $=$ Pulmonary tuberculosis; NTM $=$ nontuberculous mycobacteria

agarose gel was transfered to Uvidoc gel documentary system (Cleaver, UK) for imaging the gel. Finally, the results of NAT2 genotype and phenotype of each participant was interpreted and collected in data collection form for the statistical analysis.

\subsection{Data analysis}

The catergorical variables were presented with numbers and percentages whereas the continuous variables were presented with mean \pm standard deviation (SD). Chi-square test and Fischer' s exact test were used to analyze the association between each categorical variable and isoniazid mono-resistance whereas the comparison between continuous variables between cases and controls was analysed by unpaired t-test. $P$-value was considered to be statistically significant. Multivariate logistic regression analysis was used to evaluate the risk factors of isoniazid mono-resistance among Thai 
Table 1. Demographic data of Thai pulmonary tuberculosis patients

\begin{tabular}{|c|c|c|}
\hline Demographic data & $\begin{array}{c}\text { Isoniazid mono- } \\
\text { resistant } \\
(\mathbf{n}=\mathbf{5 0}) \\
\end{array}$ & $\begin{array}{c}\text { Drug susceptible } \\
\text { tuberculosis } \\
(\mathbf{n}=\mathbf{1 1 7}) \\
\end{array}$ \\
\hline \multicolumn{3}{|l|}{ Gender } \\
\hline Male & $31(62.0)$ & $79(67.5)$ \\
\hline Female & $19(38.0)$ & $38(32.5)$ \\
\hline \multicolumn{3}{|l|}{ Age (years) } \\
\hline Mean \pm SD & $42.32 \pm 13.68$ & $48.69 \pm 15.21$ \\
\hline$\leq 50$ years old & $36(72.0)$ & $60(51.3)$ \\
\hline$>50$ years old & $14(28.0)$ & $57(48.7)$ \\
\hline \multicolumn{3}{|l|}{ Marital status } \\
\hline Single & $12(24.0)$ & $31(26.5)$ \\
\hline Married & $30(60.0)$ & $77(65.8)$ \\
\hline Divorced / Widowed & $8(16.0)$ & $9(7.7)$ \\
\hline \multicolumn{3}{|l|}{ Educational background } \\
\hline Primary school or lower & $14(28.0)$ & $42(35.9)$ \\
\hline Secondary school or vocational certificate & $19(38.0)$ & $44(37.6)$ \\
\hline Vocational diploma & $9(18.0)$ & $8(6.8)$ \\
\hline Bachelor's degree or higher & $8(16.0)$ & $23(19.7)$ \\
\hline \multicolumn{3}{|l|}{ Occupation } \\
\hline Government officer / State enterprise officer & $10(20.0)$ & $13(11.1)$ \\
\hline Employee & $17(34.0)$ & $36(30.8)$ \\
\hline Personal business & $14(28.0)$ & $31(26.5)$ \\
\hline Unemployed & $9(18.0)$ & $37(31.6)$ \\
\hline \multicolumn{3}{|l|}{ History of imprisonment } \\
\hline Yes & $6(12.0)$ & $17(14.5)$ \\
\hline No & $44(88.0)$ & $100(85.5)$ \\
\hline \multicolumn{3}{|l|}{ History of smoking } \\
\hline Ever-smoker & $29(58.0)$ & $71(60.7)$ \\
\hline Non-smoker & $21(42.0)$ & $46(39.3)$ \\
\hline \multicolumn{3}{|l|}{ History of alcohol consumption } \\
\hline Ever-drinker & $26(52.0)$ & $86(73.5)$ \\
\hline Non-drinker & $24(48.0)$ & $31(26.5)$ \\
\hline \multicolumn{3}{|l|}{ History of INH administration } \\
\hline Ever-INH user & $13(26.0)$ & $30(25.6)$ \\
\hline Non-INH user & $37(74.0)$ & $87(74.4)$ \\
\hline \multicolumn{3}{|l|}{ Results of direct smear } \\
\hline Positive & $36(72.0)$ & $91(77.8)$ \\
\hline Negative & $14(28.0)$ & $26(22.2)$ \\
\hline \multicolumn{3}{|l|}{ TB contact in family } \\
\hline Yes & $18(36.0)$ & $41(35.0)$ \\
\hline No & $32(64.0)$ & $76(65.0)$ \\
\hline \multicolumn{3}{|l|}{ Directly observed treatment } \\
\hline Yes & $33(66.0)$ & $76(65.0)$ \\
\hline No & $17(34.0)$ & $41(35.0)$ \\
\hline \multicolumn{3}{|l|}{ History of fixed dose combination administration } \\
\hline No & $44(88.0)$ & $95(81.2)$ \\
\hline Yes & $6(12.0)$ & $22(18.8)$ \\
\hline \multicolumn{3}{|l|}{ Diabetes } \\
\hline Yes & $16(32.0)$ & $26(22.2)$ \\
\hline No & $34(68.0)$ & $91(77.8)$ \\
\hline \multicolumn{3}{|l|}{ Human immunodeficiency virus } \\
\hline Positive & $3(6.0)$ & $5(4.3)$ \\
\hline Negative & $47(94.0)$ & $112(95.7)$ \\
\hline \multicolumn{3}{|l|}{ Cavities in lungs } \\
\hline Yes & $13(26.0)$ & $45(38.5)$ \\
\hline No & $37(74.0)$ & $72(61.5)$ \\
\hline
\end{tabular}

$\mathrm{n}=$ Number, $\mathrm{SD}=$ Standard deviation, $\mathrm{INH}=$ isoniazid, $\mathrm{TB}=$ tuberculosis

pulmonary tuberculosis patients of Central Chest Institute of Thailand. Statistical analysis was performed by the Statistical Package for the Social Sciences (IBM SPSS version 21.0; International Business Machines Corp, New York, USA). 
Table 2. NAT2 genotypes and NAT2 phenotpes among Thai pulmonary tuberculosis patients

\begin{tabular}{lcc}
\hline Results of pharmacogenetic testing & $\begin{array}{c}\text { Isoniazid mono-resistant } \\
(\mathbf{n}=\mathbf{5 0})\end{array}$ & $\begin{array}{c}\text { Drug susceptible tuberculosis } \\
(\mathbf{n}=\mathbf{1 1 7})\end{array}$ \\
\hline NAT2 genotypes & $7(14.0)$ & $15(12.8)$ \\
$N A T 2 * 4 / * 4$ & $5(10.0)$ & $3(2.6)$ \\
$N A T 2 * 4 / * 5 B$ & $12(24.0)$ & $38(32.5)$ \\
$N A T 2 * 4 / * 6 A$ & $3(6.0)$ & $13(11.1)$ \\
$N A T 2 * 4 / * 7 B$ & $1(2.0)$ & $1(0.9)$ \\
$N A T 2 * 4 / * 12 A$ & $0(0.0)$ & $2(1.7)$ \\
$N A T 2 * 5 B / * 5 B$ & $2(4.0)$ & $5(4.3)$ \\
$N A T 2 * 5 B / * 6 A$ & $2(4.0)$ & $1(0.9)$ \\
$N A T 2 * 5 B / * 7 B$ & $0(0.0)$ & $1(0.9)$ \\
$N A T 2 * 5 B / * 12 A$ & $9(18.0)$ & $14(12.0)$ \\
$N A T 2 * 6 A / * 6 A$ & $5(10.0)$ & $16(13.7)$ \\
$N A T 2 * 6 A / * 7 B$ & $0(0.0)$ & $1(0.9)$ \\
$N A T 2 * 6 A / * 12 A$ & $0(0.0)$ & $3(2.6)$ \\
$N A T 2 * 6 A / * 13 A$ & $4(8.0)$ & $3(2.6)$ \\
$N A T 2 * 7 B / * 7 B$ & $0(0.0)$ & $1(0.9)$ \\
$N A T 2 * 13 A / * 13 A$ & & \\
NAT2 phenotypes & $8(16.0)$ & $17(14.5)$ \\
Rapid acetylator status & $20(40.0)$ & $60(51.3)$ \\
Intermediate acetylator status & $22(44.0)$ & $40(34.2)$ \\
Slow acetylator status & & \\
\hline
\end{tabular}

$\mathrm{n}=$ Number, NAT2 $=$ N-acetyltransferase 2

\section{RESULTS}

\subsection{Participant recruitment}

Based on B.E. year 2016-2018 registry books of TB clinic, there were suspected TB 2,325 patients who have visited TB clinic since $4^{\text {th }}$ January 2016 ; however, only 1,363 registered TB patients of Central Chest Institute of Thailand received TB treatment during the study period. Of 1,363 registered patients, the eligible patients, who started anti-TB drugs at TB clinic, Central Chest Institute of Thailand from June 2017 to September 2017, were recruited by participant screening form, comprising inclusion and exclusion criteria. Flow diagram of participant recruitment was demonstrated as shown in Figure 1. Finally, the total number of isoniazid monoresistant participants (cases) was 50 participants whereas the total number of DS-TB participants (controls) was 117 participants.

\subsection{Patients characteristics}

According to patients characteristics as shown in Table 1, common ages of cases $(72.0 \%)$ were less than 50 years old (mean $\pm \mathrm{SD}=42.32$ \pm 13.68 years old) whereas almost half of controls $(48.7 \%)$ were more than 50 years old (mean $\pm \mathrm{SD}=48.69 \pm 15.21$ years old). According to the history of alcohol consumption, the percentage of ever-drinkers $(52.0 \%)$ among cases was lower than that of controls $(73.5 \%)$.
Among 26 ever-drinkers of cases, average daily consumption was approximately $67 \mathrm{~g}$ /day with $67.02 \pm 74.52 \mathrm{~g} /$ day (mean $\pm \mathrm{SD}$ ) whereas the average daily consumption among 86 controls was approximately $41 \mathrm{~g} /$ day with $40.83 \pm 51.81$ $\mathrm{g} /$ day (mean $\pm \mathrm{SD}$ ). According to characteristics of NAT2 genotypes and phenotypes as shown in Table 2, top three NAT2 genotypes of cases were NAT2 *4/*6A (24.0\%), NAT2 *6A/*6A (18.0\%), $N A T 2 * 4 / * 4(14.0 \%)$ whereas those of controls were $N A T 2 * 4 / * 6 A(32.5 \%), N A T 2 * 6 A / * 7 B$ $(13.7 \%)$, and $N A T 2 * 4 / * 4(12.8 \%)$. However, slow acetylator $(44.0 \%)$ was found as the most common phenotype among cases whereas intermediate acetylator $(51.3 \%)$ was common among controls. Interestingly, NAT2 *4/*6A was mainly found among both cases $(24.0 \%)$ and controls $(32.5 \%)$.

\subsection{Risk factors associated with isoniazid mono-resistance}

Univaiate and multivariate logistic regression were analyzed and their OR of the factors with $95 \% \mathrm{CI}$ and their $p$-value among cases and control of Thai patients at Central Chest Institute of Thailand as shown in Table 3. The significant risk factor of isoniazid monoresistance was patient with age $\leq 50$ years old (adjusted OR, 2. 281; 95\% CI 1. 101-4. 729, pvalue $=0.027$ ), but ever-alcohol drinker was less likely to develop isoniazid mono-resistance (adjusted OR 0.417; 95\%CI 0.207-0.842, $p$-value 
Table 3. Risk factors of isoniazid mono-resistance among Thai pulmonary tuberculosis patients of Central Chest Institute at Thailand

\begin{tabular}{|c|c|c|c|c|c|c|}
\hline \multirow{2}{*}{ Demographic data } & \multicolumn{3}{|c|}{ Univariate analysis } & \multicolumn{3}{|c|}{ Multivariate analysis } \\
\hline & OR & $95 \% \mathrm{CI}$ & $p$ value & OR & $95 \% \mathrm{CI}$ & $p$ value \\
\hline \multicolumn{7}{|l|}{ Gender } \\
\hline Male & 0.785 & $0.394-1.564$ & 0.491 & & & \\
\hline Female & 1 & & & & & \\
\hline \multicolumn{7}{|l|}{ Age (years) } \\
\hline$\leq 50$ years old & 2.443 & $1.194-4.998$ & $0.013^{*}$ & 2.281 & $1.101-4.728$ & $0.027 *$ \\
\hline$>50$ years old & 1 & & & 1 & & \\
\hline \multicolumn{7}{|l|}{ Marital status } \\
\hline Single & 1.006 & $0.457-2.215$ & 0.267 & & & \\
\hline Married & 2.296 & $0.718-7.342$ & & & & \\
\hline Divorced / Widowed & 1 & & & & & \\
\hline \multicolumn{7}{|l|}{ Educational background } \\
\hline Primary school or lower & 0.958 & $0.350-2.622$ & 0.158 & & & \\
\hline Secondary school or vocational certificate & 1.241 & $0.472-3.268$ & & & & \\
\hline Vocational diploma & 3.696 & & & & & \\
\hline Bachelor's degree or higher & 1 & & & & & \\
\hline \multicolumn{7}{|l|}{ Occupation } \\
\hline Government officer / State enterprise officer & 3.162 & $1.053-9.502$ & 0.211 & & & \\
\hline Employee & 1.941 & $0.767-4.916$ & & & & \\
\hline Personal business & 1.857 & $0.708-4.868$ & & & & \\
\hline Unemployed & 1 & & & & & \\
\hline \multicolumn{7}{|l|}{ History of imprisonment } \\
\hline Yes & 0.802 & $0.296-2.172$ & 0.664 & & & \\
\hline No & 1 & & & & & \\
\hline \multicolumn{7}{|l|}{ History of smoking } \\
\hline Ever-smoker & 0.895 & $0.456-1.754$ & 0.746 & & & \\
\hline Non-smoker & 1 & & & & & \\
\hline \multicolumn{7}{|l|}{ History of alcohol consumption } \\
\hline Ever-drinker & 0.391 & $0.196-0.779$ & $0.007 *$ & 0.417 & $0.207-0.842$ & $0.015^{*}$ \\
\hline Non-drinker & 1 & & & 1 & & \\
\hline \multicolumn{7}{|l|}{ History of INH administration } \\
\hline Ever-INH user & 1.019 & $0.478-2.170$ & 0.961 & & & \\
\hline Non-INH user & 1 & & & & & \\
\hline \multicolumn{7}{|l|}{ Results of direct smear } \\
\hline Positive & 0.735 & $0.345-1.564$ & 0.423 & & & \\
\hline Negative & 1 & & & & & \\
\hline \multicolumn{7}{|l|}{ TB contact in family } \\
\hline Yes & 1.043 & $0.522-2.081$ & 0.906 & & & \\
\hline No & 1 & & & & & \\
\hline \multicolumn{7}{|l|}{ Directly observed treatment } \\
\hline Yes & 1.047 & $0.521-2.104$ & 0.897 & & & \\
\hline No & 1 & & & & & \\
\hline \multicolumn{7}{|l|}{$\begin{array}{l}\text { History of fixed dose combination } \\
\text { administration }\end{array}$} \\
\hline No & 1.698 & $0.643-4.484$ & 0.281 & & & \\
\hline \multirow{2}{*}{\multicolumn{7}{|c|}{ Diabetes }} \\
\hline & & & & & & \\
\hline Yes & 1.647 & $0.788-3.441$ & 0.182 & & & \\
\hline No & 1 & & & & & \\
\hline
\end{tabular}

$=0.015)$. Moreover, NAT2 rapid acetylator status was not the significant risk factor of isoniazid mono-resistance among Thai pulmonary tuberculosis patients of Central Chest Institute of Thailand as shown in Table 4.

\section{DISCUSSION}

In this study, the significant risk factor associated with isoniazid mono-resistance among
Thai pulmonary tuberculosis patients who received TB treatment at Central Chest Institute of Thailand was patients whose ages were equal to or less than 50 years old. On the other hand, patients who had history of alcohol consumption were less likely to develop isoniazid mono-resistance. Interestingly, rapid acetylator status was not the significant risk factor of isoniazid mono-resistance among this population, as well. Therefore, these three factors were clarified in this discussion. 
Table 4. Pharmacogenetic factors of isoniazid mono-resistance among Thai pulmonary tuberculosis patients at Central Chest Institute of Thailand

\begin{tabular}{|c|c|c|c|c|c|c|}
\hline \multirow{2}{*}{ Demographic data } & \multicolumn{3}{|c|}{ Univariate analysis } & \multicolumn{3}{|c|}{ Multivariate analysis } \\
\hline & OR & $95 \% \mathrm{CI}$ & $p$ value & OR & 95\%CI & $p$ value \\
\hline \multicolumn{7}{|l|}{ Human immunodeficiency virus } \\
\hline Yes & 1.430 & $0.328-6.227$ & 0.697 & & & \\
\hline No & 1 & & & & & \\
\hline \multicolumn{7}{|l|}{ NAT2 genotypes } \\
\hline$N A T 2 * 4 / * 4$ & 1 & & 0.352 & & & \\
\hline$N A T 2 * 4 / * 5 B$ & 3.571 & $0.659-19.341$ & & & & \\
\hline$N A T 2 * 4 / * 6 A$ & 0.677 & $0.224-2.048$ & & & & \\
\hline$N A T 2 * 4 / * 7 B$ & 0.462 & $0.098-2.172$ & & & & \\
\hline$N A T 2 * 4 / 12 A$ & 2.143 & 0.116-39.469 & & & & \\
\hline$N A T 2 * 5 B / * 5 B$ & - & - & & & & \\
\hline$N A T 2 * 5 B / * 6 A$ & 0.857 & $0.132-5.557$ & & & & \\
\hline$N A T 2 * 5 B / * 7 B$ & 4.286 & $0.330-55.585$ & & & & \\
\hline$N A T 2 * 5 B / * 12 A$ & - & - & & & & \\
\hline$N A T 2 * 6 A / * 6 A$ & 1.378 & $0.404-4.700$ & & & & \\
\hline$N A T 2 * 6 A / * 7 B$ & 0.670 & $0.174-2.574$ & & & & \\
\hline$N A T 2 * 6 A / * 12 A$ & - & - & & & & \\
\hline$N A T 2 * 64 / * 13 A$ & - & - & & & & \\
\hline$N A T 2 * 7 B / * 7 B$ & 2.857 & $0.499-16.363$ & & & & \\
\hline$N A T 2 * 13 A / * 13 A$ & - & - & & & & \\
\hline \multicolumn{7}{|l|}{ NAT2 phenotypes } \\
\hline Rapid acetylator status & 1 & & 0.389 & & & \\
\hline Intermediate acetylator status & 0.810 & $0.293-2.234$ & & & & \\
\hline Slow acetylator status & 1.169 & $0.435-3.140$ & & & & \\
\hline
\end{tabular}

Pharmacogenetics is the study of how an individual's genetic inheritance affects response to drugs ${ }^{2}$. At present, pharmacogenetics was applied in many clinical practice to achieve therapeutic effects and prevent adverse effects. In Thailand, various genotyping tests have been developed to increase safety and effectiveness for Thai patients; likewise, many previous clinical studies associated with pharmacogenetics have been conducted continuously in Thai population to support dose adjustment by individual genetic. However, there was only one genotyping test for HLA-B* 15:02 for carbamazepine therapy which has been approved to detect in Thai epileptic patients $^{6,7}$. In addition, pharmacogenetics is applied in TB treatment due to the fact that Wattanapokayakit $\mathrm{S}$, et al revealed that $71.1 \%$ Thais with AT-DILI had slow acetylator phenotype whereas a majority of AT-DILI tolerance Thais had intermediate acetylator phenotype; moreover, patients with slow acetylator were 8.80 times more likely to develop AT-DILI (OR 8. 80; 95\% CI 4.01-19.31, $p$-value $\left.=1.53 \times 10^{-8}\right)^{11}$.

Isoniazid (INH) is one of the most essential anti-TB drug among the first line antiTB drugs (FLDS), and metabolism of INH is also associated with individual genetic. To our knowledge, INH is mainly metabolized by NAT2 enzyme in a liver, and it was well known that drug-induced liver injury from INH was commonly found among patients with slow acetylator whereas poor treatment outcomes, comprising acquired drug resistance, relapse, and microbiological failure, were more likely to occur among patients with rapid acetylator ${ }^{2,8,9}$. In this study, NAT2 *4/*4 was selected as a reference genotype because NAT2 *4 was a wildtype allele in the case of absence of SNPs; consequently, a homozygous genotype NAT2 $* 4 / * 4$ was considered as rapid acetylator. The results showed that Thai patients with rapid acetylator were less likely to develop isoniazid mono-resistance during the treatment when compared with Thai patients who had slow acetylator (OR 1.169; 95\% CI 0.435-3.140; $p$ value $=0.389$ from Table 4). This result was inconsistent with general principle because patients with a high rate of INH metabolism were more likely to resist to INH because of low INH plasma concentration, and this result was also different from other previous studies. According to one of the previous study from Japan, oral 300 mg INH was administered to healthy Japanese males with rapid acetylator $(\mathrm{n}=8)$ and intermediate acetylator $(\mathrm{n}=8)$ and the pharmacokinetic parameters were estimated from plasma INH concentration for $24 \mathrm{hr}$ post dose. 
Kubota $\mathrm{R}$, et al found that patients with rapid acetylator had lower AUC $(9.54 \pm 0.85 \mathrm{mg} * \mathrm{hr} / \mathrm{L})$ than that of patients with intermediate acetylator $\left(14.21 \pm 0.62 \mathrm{mg}^{*} \mathrm{hr} / \mathrm{L}\right)(p$-value $<0.05){ }^{27}$. Similarly to the study from South Korea, after 153 newly active TB patients had been administered $300 \mathrm{mg}$ INH for 6 months, Jung JA, et al found that the 2-hr post-dose concentrations of INH of patients with rapid acetylator (2.25 $\mathrm{mg} / \mathrm{L}$ ) was significantly less than that of patients with intermediate acetylator and slow acetylator $(2.25 \mathrm{mg} / \mathrm{L}, 6.78 \mathrm{mg} / \mathrm{L})(p \text {-value }<0.001)^{28}$. Similarly to the study of Kinzing-Schippers M, et al INH was randomly administered in order as a $100 \mathrm{mg}$ oral INH, a $300 \mathrm{mg} \mathrm{INH}$ (with vitamin B6 $60 \mathrm{mg}$ ), and $200 \mathrm{mg}$ intravenous infusion single dose to 18 healthy Caucasians, to assess individual INH exposure based on NAT2 genotype. It was found that participants who had two high-activity alleles $(N A T 2 * 4 / * 4)$ were reported to show lower AUC and the maximum concentration $\left(\mathrm{C}_{\max }\right)$ than participants who had one or no NAT2 $* 4$ allele $(p \text {-value }<0.01)^{29}$. However, participants of this current study were definitely different from those of the previous study since thier ethnicitiy was Thai and all of them were diagnosed as pulmonary tuberculosis patients. For TB treatment during data collection, this study did not control and screen the duration of INH administration, dose of INH of each participant $(\mathrm{mg} / \mathrm{kg} /$ day), drug-drug interaction, and drug-food interaction before data collection. Moreover, the researcher did not recruite healthy partcipants for saliva sample collection and NAT2 genotyping test; consequently, the researcher could not compare the difference of NAT2 genotypes between healthy participants and pulmonary tuberculosis participants. Interestingly, some previous studies revealed that metabolism of INH was not only related to rate of NAT2 enzyme activity, but also another drugmetabolizing enzyme, i.e. CYP2E1 enzyme.

Based on literature review, the prevalence of TB was commonly found in the elderly, but DR-TB could affect all ranges of age. In this study, Thai pulmonary tuberculosis patients whose ages were equal to or less than 50 years old were more likely to develop isoniazid mono-resistance (adjusted OR $=2.281$ ) as compared to patients whose ages were more than 50 years old $(p$-value $=0.027)$. At the present, there were not any previous studies which could explain why younger adults were significantly associated with isoniazid mono-resistance, but this study could show details of isoniazid mono- resistant participants. In this study, $30.0 \%$ of their ages were in range of $41-50$ years old (mean \pm $\mathrm{SD}=42.32 \pm 13.68$ years old; $\min -\max =18$ 80 years old). Most of isoniazid mono-resistant participants earned a living by being employee $(34.0 \%)$ and personal business (28. 0\%). Therefore, they might experience the severe working environmental condition; including poor aeration and low air ventilation in their room; as a result, TB pathogens could transmit from TB infected patients to non-infected patients. Moreover, some employees might not know that they have already infected with TB pathogens due to no signs and symptoms; therefore, they did not prevent TB transmission by wearing hygienic mask or seeing a physician. According to previous studies, some studies revealed that there was not association between age and isoniazid mono-resistance, especially the study in Thailand. Traisathit $\mathrm{P}$, et al reported that the mean age of 126 isoniazid mono resistant patients from 36 hospitals in the northern region of Thailand was $49.8 \pm 17.70$ years old and 378 DSTB patients from those hospitals was $49.8 \pm$ 17. 60 years old whose ages closed to the present study which from single site data collection ${ }^{25}$. However, the present study was similar to Hoopes AJ, et al who found that young adults (15-44 years old) were more likely to have isoniazid mono-resistance. The patients with 1524 years old group revealed adjusted OR 1.50 (99\%CI 1.30-1.70) whereas with 25-44 years old: adjusted OR $1.5099 \%$ CI 1.40-1.70 ${ }^{18}$. These patients of the US study were collected from the National Tuberculosis Surveillance System (NTSS) at the US Centers for Disease Control and Prevention (CDC) during 1993 to 2003 which differed from the present study ${ }^{18}$. The various patients in term of ethnicity from this study were not the same as Thai patients. In contrast, young adults in Germany were not more likely to be at risk of isoniazid mono-resistance. It was found that the patients with 15-24 years old group were calculated adjusted OR by 1.40 $(95 \%$ CI $0.70-2.80, p$-value $=0.293)$ and with 25 34 years old group were adjusted OR 1.1 (95\% CI $0.60-2.10, p$-value $=0.834)$ whereas only $27-34$ years old foreign-born TB patients in Germany were significantly associated with isoniazid mono-resistance by adjusted OR $0.26(95 \% \mathrm{CI}$ $0.17-0.40, p$-value $<0.001)^{12}$. One reason that could explain that finding was almost foreignborn patients in Germany were immigrants from other countries with severe TB problems and poor TB control, i.e. Africa, Asia, Turkey, and 
the Newly Independent States of the former Soviet Union ${ }^{12}$. Moreover, the result of the present study was differred from the study of Varahram $\mathrm{M}$ and colleagues who reported that Iranian patients whose ages were less than 45 years old were less likely to develop isoniazid mono-resistance by OR 0.62 (95\% CI 0.39-0.97, $p$-value $=0.03)$. This finding caused by the distribution of isoniazid mono-resistant group by $62.3 \%$ reported ethinicity of patients from the patients from all regions of Iran, and the highest proportions of isoniazid mono-resistant group were $62.3 \%$ with age above 45 years old ( $p$-value $=0.03$ ). This result could reflect that previously treated cases with DR-TB occured generally among older patients ${ }^{24}$.

According to the association between TB and alcohol consumption, alcohol abuse has been associated with unsuccessful treatment for TB. Especially, alcohol consumption during multidrug-resistant tuberculosis (MDR-TB) treatment had a higher risk for poor treatment outcome than those who did not i.e. Hazard Ratio (HR) 4.90 (95\% CI 1.20-20.30) since alcohol was able to decrease antigen-specific Tcell activation and suppress cytokine production ${ }^{30}$. Regarding to prior studies associated with pharmacokinetics, acetylation of sulfadimidine and procainamide has been increased by alcohol consumption whereas administration of ethanol in mice $(1.5 \mathrm{mg} / \mathrm{g}$ and $4 \mathrm{mg} / \mathrm{g}$ IV) could increase the concentration of acetylisoniazid (AcINH) which is metabolite of INH; however, the effects of alcohol on INH pharmacokinetics have not been clearly reported in human 31,32 . Interestingly, this current study revealed that pulmonary tuberculosis patients who were everdrinkers were less likely to have isoniazid mono-resistance (adjusted OR 0.417; 95\% CI $0.207-0.842, p$-value 0.015 ). Like the previous study, Villegas L, et al found that patients with high alcoholism were less likely to have isoniazid mono-resistance among 1,039 pulmonary tuberculosis patients in a northern district of Lima, Peru (adjusted OR 0.52 95\%CI $0.30-1.10){ }^{15}$. Similarly to the studies associated with the effects of acute alcohol intake in pharmacokinetics of INH, Wilcke JTR, et al reported that acute alcohol intake did not impact on the conversion of the pharmacokinetic parameters, including $\mathrm{C}_{\max }$, the time to reach $\mathrm{C}_{\max }\left(\mathrm{T}_{\max }\right)$, the half-life $\left(\mathrm{t}_{1 / 2}\right)$, AUC of either INH or AcINH ( $p$-value $>0.05$ ) among 2 healthy women and 8 healthy men, aged 22-50 years old, after an oral dose of $300 \mathrm{mg}$ INH had been administered on 2 separate days, 2 weeks apart, with or without a loading dose of $0.73 \mathrm{~g}$ absolute ethanol ( $96 \mathrm{v} / \mathrm{v} \%$ ethanol $/ \mathrm{kg}$ ) followed by a maintenance of $0.11 \mathrm{~g}$ ethanol $/ \mathrm{kg} / \mathrm{hr}$ for 12 $\mathrm{hr}^{33}$. In addition, Dattani RG, et al also found that there was no significant difference in AUC, $\mathrm{C}_{\max }, \mathrm{T}_{\max }, \mathrm{t}_{1 / 2}$, and the ratio of AcINH/INH in blood sample withdrawn $3 \mathrm{hr}$ after INH dose for either healthy males (18-31 years old) with slow acetylator or rapid acetylator, after each participant had received ethanol $0.73 \mathrm{~g} / \mathrm{kg}, 1 \mathrm{hr}$ before an oral dose of $200 \mathrm{mg} \mathrm{INH}$, followed by $0.11 \mathrm{~g} / \mathrm{kg}$ ethanol orally every hour thereafter for $1 \mathrm{hr}{ }^{34}$. To our knowledge, CYP2E1 is another enzyme which can oxidize an intermediate of INH into hepatotoxins. In humans, CYP2E1 of non-alcoholic person is only responsible for oxidizing $10 \%$ of alcohol whereas high blood alcohol concentration of chronic alcohol drinker could increase CYP2E1 level, which allows the enzyme to play a major role in alcohol metabolism. Therefore, TB patients who drink alcohol during INH administration have a higher risk to have hepatotoxins, i.e. acetyl diazine, ketene, acetyl radical, since isoniazid hydrazine, which is a metabolite of INH, is oxidized rapidly by CYP2E1 to form N-hydroxy-acetyl hydrazine. Then N-hydroxy-acetyl hydrazine is dehydrated to yield acetyl diazine which is toxic metabolite. As a result, most of the chronic alcohol drinkers with TB were more likely to have AT-DILI by alcohol-mediated induction of CYP2E1. In contrast, non-alcoholic persons have a higher risk to have non-active metabolite because there was no alcohol which can induce CYP2E1. Consequently, isoniazid hydrazine, which is a toxic metabolite of INH, can be metabolized by NAT2 enzyme in another pathway to yield diacetyl hydrazin, and then excreted in the urine. As a consequence, INH plasma concentration among non-alcoholic persons is not enough to eradicate $M$. tuberculosis in TB patients ${ }^{35,}{ }^{36}$. Besides alcohol consumption, polymorphisms of $C Y P 2 E 1$ gene also affect activity or level of the CYP2E1 enzyme and affect susceptibility to AT-DILI. Meta-analysis of 26 studies revealed that the CYP2E1 RsaI/PstI Cl/Cl genotype was significantly associated with AT-DILI (OR 1.32, $95 \%$ CI $1.03-1.69, p$-value $=0.027)$, especially among East Asians ${ }^{37}$. Moreover, another metaanalysis showed that patients with CYP2E1 $C 1 / C 1$ who were NAT2 slow acetylators had higher risk for AT-DILI (OR 3.10, 95\%CI 1.83$5.26, p$-value $<0.0001)^{38}$. One study of Thailand 
revealed that CYP2E1 RsaI/PstI Cl/Cl was the most common alleles $(73.2 \%)$ among 485 healthy Thais ${ }^{39}$. As a consequence, the main partway of metabolism of isoniazid among Thai PTB patients who were ever-drinker might be the partway which can oxidize the intermediate of INH into hepatotoxins, and they might have higher risk for AT-DILI. However, this present study did not determine genetic polymorphisms of CYP2Elof Thai population; therefore, the researchers should be encouraged to do more similar researches among the Thai population to support these results.

The limitation of this study was the number of participants that was still low, compared with the number of participants of other previous studies. The duration of INH administration and average dose per kg per day of INH of each participant were not controlled in participant recruitment; however, daily dose of INH of all participants was $300 \mathrm{mg} /$ day. Moreover, data of drug-drug interactions and drug-food interaction during TB treatment of each participant were not reported in medical records; therefore, the researcher did not know what medicine or food could affect the pharmacokinetic or pharmacodinamic of INH.

\section{CONCLUSIONS}

The surveillance of patients with age less than 50 years old and never alcohol drinker should be monitored for isoniazid monoresistance in Thai pulmonary tuberculosis patients, and NAT2 genotypes might not be detected for monitoring the reisistance of INH among Thai pulmonary tuberculosis patients.

\section{ACKNOWLEDGEMENTS}

\section{Conflict of interest}

The authors declare that there are no conflicts of interest.

\section{Funding}

This study received funding for NAT2 genotyping test from Department of Medical Sciences.

\section{Ethical approval}

This study was conducted under the approval of Faculty of Dentistry/Faculty of Pharmacy, Mahidol University Institutional Review Board (MU-DT/PT IRB 2017/031.1605) and the approval of Ethics Committee of CCIT.

\section{Article info:}

Received August 1, 2019

Received in revised form October 21, 2019

Accepted November 2, 2019

\section{REFERENCES}

1. Chierakul N, Saengthongpinij V, Foongladda S. Clinical features and outcomes of isoniazid mono-resistant pulmonary tuberculosis. J Med Assoc Thai. 2014;97(3):S86-90.

2. Sukasem C, Puangpetch A, Medhasi S, Tassaneeyakul W. Pharmacogenomics of drug-induced hypersensitivity reactions: challenges, opportunities and clinical implementation. Asian Pac J Allergy Immunol. 2014;32(2):111-23.

3. Singh N, Dubey S, Chinnaraj S, Golani A, Maitra A. Study of NAT2 gene polymorphisms in an indian population association with plasma isoniazid concentration in a cohort of tuberculosis patients. Mol Diag Ther. 2009;13(1):49-58.

4. Yuliwulandari R, Susilowati RW, Mahasirimongkol S, Wicaksono BD, Viyati K, Prayuni K, et al. NAT2 variants are associated with drug-induced liver injury caused by anti-tuberculosis drugs in indonesian patients with tuberculosis. J Hum Genet. 2016:1-5.

5. Banerjee $M$. Arylamine $\mathrm{N}$-acetyltransferase 2 polymorphism in the ethnic populations of South India. Int J Mol Med. 2003;11:125-31.

6. Bu R, Gutiérrez MI, Al-Rasheed M, Belgaumi A, Bhatia $\mathrm{K}$. Variable drug metabolism genes in Arab population. Pharmacogenomics J. 2004;4:260-6.

7. Loktionov A, Moore W, Spencer SP, Vorster H, Nell T, O'Neill IK, et al. Differences in N-acetylation genotypes between caucasians and black South Africans: Implications for cancer prevention. Cancer Detect Prev. 2002;26:15-22.

8. Hiratsuka M, Kishikawa Y, Takekuma Y, Matsuura M, Narahara $K$, Inoue $T$, et al. Genotyping of the $\mathrm{N}$ acetyltransferase 2 polymorphism in the prediction of adverse drug reactions to isoniazid in Japanese patients. Drug Metab Pharmacokinet. 2002;17:357-62.

9. Chen B, Li JH, Xu YM, Wang J, Cao XM. The influence of NAT2 genotypes on the plasma concentration of isoniazid and acetylisoniazid in Chinese pulmonary tuberculosis patients. Clin Chim Acta. 2006;365:104-8.

10. Kukongviriyapan V, Prawan A, Tassaneyakul W, Aiemsa-Ard J, Warashiha B. Arylamine Nacetyltransferase- 2 genotypes in the Thai population. $\mathrm{Br}$ J Clin Pharmacol. 2003;55:278-81.

11. Wattanapokayakit $\mathrm{S}$, Mushiroda $\mathrm{T}$, Yanai $\mathrm{H}$, Wichukchinda N, Chuchottaworn C, Nedsuwan S, et al. NAT2 slow acetylator associated with anti-tuberculosis drug-induced liver injury in Thai patients. Int $\mathbf{J}$ Tuberc Lung Dis. 2016;20(10):1364-9.

12. Forssbohm M, Loddenkemper R, Rieder HL. Isoniazid resistance among tuberculosis patients by birth cohort in Germany. Int J Tuberc Lung Dis. 2003;7(10):973-9.

13. Hsu AH, Lee JJ, Chiang CY, Li YH, Chen LK, Lin CB. Diabetes is associated with drug-resistant tuberculosis in eastern Taiwan. Int J Tuberc Lung Dis. 2012;17(3):354-6.

14. Fox L, Kramer MR, Haim I, Priess R. Comparison of isoniazid mono-resistant tuberculosis with drugsusceptible tuberculosis and multidrug-resistant tuberculosis. Eur J Clin Microbial Infect Dis. 2011;30:863-7.

15. Villegas L, Otero L, Sterling TR, Huaman MA, Gotuzzo $\mathrm{E}$, Seas C, et al. Prevalence, risk factors, and treatment 
outcomes of isoniazid-and rifampicin-mono-resistant pulmonary tuberculosis in Lima, Peru. Plos One. 2016;11(4):1-11.

16. Ruddy M, Balabanova Y, Graham C, Fedorin I, Malomanova N, Elisarova E, et al. Rates of drug resistance and risk factor analysis in civilian and prison patients with tuberculosis in Samara region, Russia. Thorax. 2005;60:130-5.

17. Cattamanchi A, Grinsdale J, Kawamura M, Osmond D, Nahid P, Dantes RB, et al. Clinical characteristics and treatment outcomes of isoniazid mono-resistant tuberculosis. Clin Infect Dis. 2009;48(2):179-85.

18. Hoopses AJ, Kammerer JS, Harrington TA, Armstrong LR, Ijaz K. Isoniazid mono-resistant tuberculosis in the United States, 1993 to 2003. Arch Intern Med. 2008;169(18):1984-92.

19. Asch S. Relationship of isoniazid resistance to hiv infection in patients with tuberculosis. Am J Respir Crit Care Med. 1996;153:1708-10.

20. Frieden TR, Sterling T, Pablos-Mendez A, Kilburn JO, Cauthen GM, Dooley SW. The emergence of drug resistant tuberculosis in New York City. N Engl J Med. 1993;328:521-6

21. Liu Z, Shilkret KL, Finelli L. Epidemiology of drug resistant tuberculosis in New Jersey from 1991-1995. Int J Epidemiol. 1998;27:121-6.

22. Magulre H, Brallstford S, Carless J, Yates M, Altass L, Yates S, Anaraki S, et al. Large outbreak of isoniazidmono-resistant tuberculosis in London, 1995 to 2006: Case-control study and recommendations. Euro Surveill. 2011;16(13):1-9.

23. Saldaña RB, Sánchez GD, Garcia LG, Cruz-Hervert LP, Castillo MM, Reyes LF, et al. Isoniazid mono-resistant tuberculosis: impact on treatment outcome and survival of pulmonary tuberculosis patients in Southern Mexico 1995-2010. Plos One. 2016;11(12):1-16

24. Varahram M, Nasiri MJ, Farnia P, Mozafari M, Velayati AA. A Retrospective analysis of isoniazid-monoresistant tuberculosis: Among Iranian pulmonary tuberculosis patients. Open Microbiol J. 2014;8:1-5.

25. Traisathit P, Pokaew T, Chanwong S, Klinbuauaem V, Wongsabuta J, Chuchottaworn C. Risk factor for isoniazid-resistance among pulmonary tuberculosis patients in Nortern Thailand. J Stat Manag Syst. 2011;14(5):899-913.

26. Rihes.cmu.ac.th [Internet]. Thailand: Research Institute for Health Sciences [updated 2016 July 7; cited 2017 Aug 31]. Available from: http://www.rishes.cmu.ac.th

27. Kubota R, Ohno M, Hasunuma T, Iijima H, Azuma J.
Dose-escalation study of isoniazid in healthy volunteers with the rapid acetylator genotype of arylamine Nacetytransferase 2. Eur J Clin Pharmacol. 2007;63:927-33.

28. Jung JA, Kim TE, Lee H, Jeing BH, Park HY, Kwon OJ, et al. A proposal for an individualized pharmacogeneticguided isoniazid dosage regimen for patients with tuberculosis. Drug Des Dev Ther. 2015;9:5433-8.

29. Kinzig-Schippers M, Tomalik-Scharte D, Jetter A, Scheidel B, Jakob V, Rodamer M, et al. Should we use $\mathrm{N}$-acetyltransferase type 2 genotyping to personalize isoniazid doses?. Antimicrob Agents Chemother. 2005;49(5):1733-8.

30. Duraisamy K, Mrithyunjayan S, Ghosh S, Nair SA, Balakrishan S, Subramoniapillai J, et al. Does alcohol consumption during multidrug-resistant tuberculosis treatment affect outcome?: A population-based study in Kerala, India. Ann Am Thorac Soc. 2014;11(5):712-8.

31. Olsen H, Morland J. Ethanol-induced increase in drug acetylation in man and isolated rat liver cells. BMJ. 1978:2:1260-2

32. Estler CJ. Effect of ethanol on levels of isoniazid, sulfanilamide and sulfapyridin in mouse blood. Experientia 35;368-9.

33. Wilcke JTR, Dossing M, Angelo HR, Askgaard D, Ronn A, Christensen HR. Unchanged acetylation of isoniazid by alcohol intake. Int $\mathrm{J}$ Tuberc Lung Dis. 2004;8(11):1373-6.

34. Dattani RG, Harry F, Hutchings AD, Routledge PA. The effects of acute ethanol intake on isoniazid pharmakicinetics. Eur J Clin Pharmacol. 2004;60:679-82.

35. Cederbaum AL. Alcohol metabolism. Clin Liver Dis. 2012;4(16):667-85.

36. Cross FS, Long MW, Banner AS. Rifampin-isoniazid therapy of alcoholic and non-alcoholic tuberculous patients in a U.S. public health service cooperative therapy trial. Am Rev Respir Dis. 1980;122:349-53.

37. Wang FJ, Wang Y, Niu T, Lu WX, Sandford AJ, He JQ. Update meta-analysis of the CYP2E1 RsaI/PstI and DraI polymorphisms and risk of antituberculosis druginduced hepatotoxicity: Evidence from 26 studies. J Clin Pharm Ther. 2016;41:334-40.

38. Sheng YJ, Wu G, He HY, Chen W, Zou YS, Li Q, et al. The association between CYP2E1 polymorphisms and hepatotoxicity due to anti-tuberculosis drug: A metaanalysis. Infect Genet Evol. 2014;24:34-40.

39. Sangrajrang S, Jedpiyawongse A, Srivatanakul P. Genetic polymorphisms of CYP2E1 and GSTM1 in a Thai population. Asian Pacific J Cancer Prev. 2006;6(7):415-9. 